\title{
The effects of behavior and attitudes on drop-off recycling activities
}

\begin{abstract}
To reduce the amount of waste entering landfills, policymakers and governments have implemented various recycling and waste reduction programs such as source reduction, curbside recycling and drop-off recycling programs. The success of a recycling program largely depends on household participation and sorting activities. A better understanding of recycling behavior will help us aid the design and improve the effectiveness of recycling policies. This paper studies the profile of people who utilize drop-off recycling sites and analyzes the factors influencing their site usage. The results show that the usage of drop-off recycling sites is influenced by demographic factors such as age, education, income and household size. Attitudinal factors are also found to affect site usage. Recyclers tend to use the drop-off sites more when they feel that recycling is a convenient activity and when they are more familiar with the sites.
\end{abstract}

Keyword: Recycling, Drop-off programs, Drop-off sites, Curbside programs, Waste management, Recycling behavior 